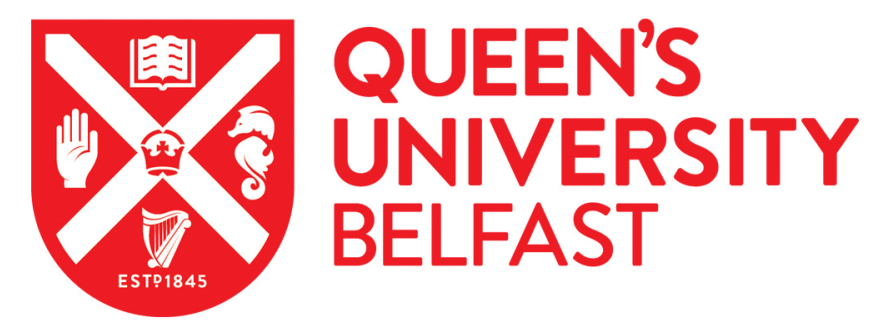

\title{
Mechanisms of silicon-mediated alleviation of abiotic stresses in higher plants: A review
}

Liang, Y. C., Sun, W. C., Zhu, Y. G., \& Christie, P. (2007). Mechanisms of silicon-mediated alleviation of abiotic stresses in higher plants: A review. Environmental Pollution, 147(2), 422-428.

https://doi.org/10.1016/j.envpol.2006.06.008

Published in:

Environmental Pollution

Queen's University Belfast - Research Portal:

Link to publication record in Queen's University Belfast Research Portal

\section{General rights}

Copyright for the publications made accessible via the Queen's University Belfast Research Portal is retained by the author(s) and / or other copyright owners and it is a condition of accessing these publications that users recognise and abide by the legal requirements associated with these rights.

Take down policy

The Research Portal is Queen's institutional repository that provides access to Queen's research output. Every effort has been made to ensure that content in the Research Portal does not infringe any person's rights, or applicable UK laws. If you discover content in the Research Portal that you believe breaches copyright or violates any law, please contact openaccess@qub.ac.uk. 


\title{
Mechanisms of silicon-mediated alleviation of abiotic stresses in higher plants: A review
}

\author{
Yongchao Liang ${ }^{\mathrm{a}, *}$, Wanchun Sun $^{\mathrm{a}}$, Yong-Guan Zhu ${ }^{\mathrm{b}}$, Peter Christie ${ }^{\mathrm{c}}$ \\ ${ }^{a}$ Ministry of Agriculture Key Laboratory of Plant Nutrition and Nutrient Cycling, Institute of Soil and Fertilizer, \\ Chinese Academy of Agricultural Sciences, Beijing 100081, China \\ ${ }^{\mathrm{b}}$ Research Center for Eco-environmental Sciences, Chinese Academy of Sciences, Beijing 100085, China \\ ${ }^{\mathrm{c}}$ Department of Agricultural and Environmental Science, Queen's University Belfast, Newforge Lane, Belfast BT9 5PX, UK
}

Received 24 May 2006; accepted 15 June 2006

This review article overviews roles Si plays in alleviating abiotic stress in higher plants and discusses future research directions.

\begin{abstract}
Although silicon ( $\mathrm{Si}$ ) is the second most abundant element both on the surface of the Earth's crust and in soils, it has not yet been listed among the essential elements for higher plants. However, the beneficial role of Si in stimulating the growth and development of many plant species has been generally recognized. Silicon is known to effectively mitigate various abiotic stresses such as manganese, aluminum and heavy metal toxicities, and salinity, drought, chilling and freezing stresses. However, mechanisms of Si-mediated alleviation of abiotic stresses remain poorly understood. The key mechanisms of Si-mediated alleviation of abiotic stresses in higher plants include: (1) stimulation of antioxidant systems in plants, (2) complexation or co-precipitation of toxic metal ions with $\mathrm{Si}$, (3) immobilization of toxic metal ions in growth media, (4) uptake processes, and (5) compartmentation of metal ions within plants. Future research needs for Si-mediated alleviation of abiotic stresses are also discussed.

(C) 2006 Elsevier Ltd. All rights reserved.
\end{abstract}

Keywords: Abiotic stress; Heavy metals; Plant disease; Salinity; Silicon

\section{Introduction}

Silicon ( $\mathrm{Si}$ ) is the second most abundant element both on the surface of the Earth's crust and in the soils. Silicon is present as silicic acid in the soil solution at concentrations normally ranging from 0.1 to $0.6 \mathrm{mM}$, roughly two orders of magnitude higher than the concentrations of phosphorus in soil solutions (Epstein, 1994, 1999).

Although Si has not been considered as an essential element for higher plants, it has been proved to be beneficial for the healthy growth and development of many plant species,

\footnotetext{
* Corresponding author. Tel.: +86106891 8657; fax: +861068975161.

E-mail address: ycliang@caas.ac.cn (Y. Liang).
}

particularly graminaceous plants such as rice and sugarcane and some cyperaceous plants (Epstein, 1994, 1999; Liang, 1999; Ma et al., 2001a; Liang et al., 2005a). The beneficial effects of $\mathrm{Si}$ are particularly distinct in plants exposed to abiotic and biotic stresses (Epstein, 1994, 1999; Ma, 2004). However, Epstein and Bloom (2005) have recently modified the nearuniversally accepted definition of essentiality of elements established by Arnon and Stout (1939). Based on this newlyestablished definition, an element is essential that fulfils either one or both of the following criteria: (1) the element is part of a molecule which is an intrinsic component of the structure or metabolism of the plant, and (2) the plant can be so severely deficient in the element that it exhibits abnormalities in growth, development, or reproduction, i.e. 'performance', compared to plants with lower deficiency. Accordingly, $\mathrm{Si}$ 
will be an essential element for higher plants, which is to be generally accepted in the near future.

Over last two decades, more extensive and intensive studies have been performed aiming at better understanding of the possible mechanism(s) for Si-enhanced resistance and/or tolerance of higher plants to both abiotic and biotic stresses (Horst and Marschner, 1978; Horiguchi and Morita, 1987; Hodson and Evans, 1995; Liang, 1999; Epstein, 1999; Liang et al., 2003; 2005a,c; Gong et al., 2005; Guo et al., 2005). More recently, rapid progress has been made in Si uptake and transport in higher plants. In this paper we review current knowledge on the roles of $\mathrm{Si}$ in conferring tolerance to plants against abiotic stresses together with Si uptake mechanisms, and then discuss recommended future research directions.

\section{Silicon uptake mechanisms}

Silicon concentrations vary greatly in plant aboveground parts, ranging from 0.1 to $10.0 \%$ of dry weight. This wide variation in $\mathrm{Si}$ concentration in plant tissues is attributed mainly to differences in the characteristics of Si uptake and transport (Jones and Handreck, 1967; Jarvis, 1987; Epstein, 1994). In general, graminaceous plants take up much more Si than other species, while most dicotyledonous plants absorb Si passively and some dicots such as legumes exclude Si from uptake (Ma et al., 2001a; Liang et al., 2005b). Silicon uptake and transport in rice, a typical $\mathrm{Si}$-accumulator, is an active process (Lewin and Reimann, 1969; Epstein, 1994; Ma et al., 2006), but some dicots such as cucumber, melon, strawberry and soybean (Takahashi et al., 1990; Ma et al., 2001a; Mitani and Ma, 2005) take up Si passively, and tomato (Takahashi et al., 1990; Mitani and Ma, 2005) and bean (Jones and Handreck, 1967; Liang et al., 2005b) exclude Si from uptake. Besides rice, other graminaceous plants such as wheat (Van der Vorm, 1980; Jarvis, 1987; Casey et al., 2003), ryegrass (Jarvis, 1987), and barley (Barber and Shone, 1966) and some cyperaceous plants take up Si actively, while certain other Gramineae such as oats take it up passively (Jones and Handreck, 1965). Rapid progress has recently been made in characterizing $\mathrm{Si}$ uptake and transport in rice by using rice mutants (Ma et al., 2002; Tamai and Ma, 2003). Ma and co-workers believe that lateral roots of rice play an important role in Si uptake while root hairs do not contribute to Si uptake (Ma et al., 2001b). Silicon uptake by rice is a specific transporter-mediated process and the transporter containing Cys residues but not Lys residues is not inducible and has a low affinity for $\mathrm{Si}$ $\left(K_{\mathrm{m}}=0.32 \mathrm{mM}\right) \quad$ (Tamai and Ma, 2003). Furthermore, a gene responsible for xylem loading of $\mathrm{Si}$ has recently been mapped to chromosome 2 of rice using the Lsil mutant (formerly GR1 mutant) and is localized on the plasma membrane of the distal side of both exodermis and endodermis cells and constitutively expressed in the roots (Ma et al., 2006). The Si gene Lsil is predicted to encode a membrane protein similar to water channel proteins (aquaporins) (Ma et al., 2006). In contrast to the rapid progress that has been made in characterizing Si uptake by rice, little information is available on Si uptake and transport in the other monocots and in dicots (Liang et al., 2005b). More recently, Mitani and Ma (2005) have reported that the $\mathrm{Si}$ concentration was lower in the xylem sap of cucumber than in the external solution, suggesting that xylem loading of Si was mediated by a passive diffusion mechanism in cucumber. However, Liang and his colleagues have demonstrated that $\mathrm{Si}$ uptake and transport are also active processes in Cucumis sativus L. (Liang et al., 2005b). Such distinct discrepancy in Si uptake and xylem loading in $\mathrm{Cucu}$ mis sativus might be caused by the different methods used for collecting xylem sap and the pre-culture of the plants, and/or by different cultivars studied. It appears that further investigation is needed to characterize Si uptake and transport in $\mathrm{Cucu}$ mis sativus. More recently, it has been reported that both active and passive mechanisms are operating in Si uptake and transport in the same $\mathrm{Si}$-accumulator such as rice and maize and intermediate type species such as sunflower and wax gourd with their contribution being dependent upon plant species and external Si concentrations (Liang et al., in press).

\section{Mechanisms for silicon-mediated alleviation of metal toxicity}

Silicon-mediated alleviation of (heavy) metal toxicity in higher plants is widely accepted. In 1957 Williams and Vlamis (1957a,b) discovered that Mn toxicity in barley in solution culture was alleviated by addition of a small amount of Si. Recently the role of silicon in mitigating Mn toxicity has been investigated extensively in barley (Horiguchi and Morita, 1987), rice (Okuda and Takahashi, 1962), bean (Horst and Marschner, 1978), pumpkin (Iwasaki and Matsumura, 1999), cowpea (Iwasaki et al., 2002a,b) and cucumber (Rogalla and Römheld, 2002; Shi et al., 2005b).

Williams and Vlamis (1957a,b) discovered for the first time that total $\mathrm{Mn}$ in the leaves was unaffected by Si but Si caused Mn to be more evenly distributed instead of being concentrated in discrete necrotic spots. This finding has been supported by subsequent experiments (Horst and Marschner, 1978; Horiguchi and Morita, 1987; Shi et al., 2005b). Horst et al. (1999) observed that Si lowered the apoplastic Mn concentration in cowpea, suggesting that Si may modify the cation binding capacity of the cell wall. Iwasaki et al. (2002a,b) found that the Mn concentration in the apoplastic washing fluids of plants with a continuous supply of $1.44 \mathrm{mM} \mathrm{Si}$ and $50 \mu \mathrm{M} \mathrm{Mn}$ and not showing Mn toxicity symptoms was higher than that of plants grown at $10 \mu \mathrm{M} \mathrm{Mn}$ without Si supply which showed distinct Mn toxicity symptoms, suggesting that Si supply alleviates Mn toxicity not only by decreasing the concentration of soluble apoplastic Mn through enhanced adsorption of $\mathrm{Mn}$ on the cell walls, but also a role of soluble $\mathrm{Si}$ in the apoplast in the detoxicification of apoplastic $\mathrm{Mn}$ is indicated. Further research indicated that the severity of Mn toxicity symptoms and guaiacol-peroxidase (POD) activity in the apoplastic washing fluid (AWF) of these plants were not significantly correlated with the Mn concentrations in AWF, but were highly significantly correlated with the Si concentrations in AWF (Iwasaki et al., 2002b). These results suggest that Si may affect the oxidation process of excess $\mathrm{Mn}$ 
mediated by POD through interaction with phenolic substances in the solution phase of the apoplast, maintaining the apoplast in a reduced state, which is thought to be a requirement for improved Mn tolerance of the leaf tissue. Almost at the same time, Rogalla and Römheld (2002) conducted similar experiments with cucumber. Their findings clearly showed that plants not treated with Si had higher Mn concentrations in the intercellular washing fluid (IWF) compared with plants treated with $\mathrm{Si}$, especially in the $\mathrm{BaCl}_{2^{-}}$and DTPA-exchangeable fractions of the leaf apoplast despite approximately the same total $\mathrm{Mn}$ content in the leaves. The Mn concentration of the IWF was positively correlated with the severity of Mn-toxicity symptoms and negatively correlated with the Si supply (Rogalla and Römheld, 2002). Furthermore, in Si-treated plants less $\mathrm{Mn}$ was located in the symplast $(<10 \%)$ and more Mn was bound to the cell wall $(>90 \%)$ compared with non-Si-treated plants (about 50\% in each compartment). Manganese present in Si-treated plants is therefore less available and for this reason less toxic than in plants not treated with Si (Rogalla and Römheld, 2002). These authors also drew the conclusion that $\mathrm{Si}$-mediated tolerance of $\mathrm{Mn}$ in C. sativus is a consequence of stronger binding of $\mathrm{Mn}$ to cell walls and a lowering of the $\mathrm{Mn}$ concentration within the symplast.

More recently, it has been reported that the alleviation of $\mathrm{Mn}$ toxicity by $\mathrm{Si}$ in cucumber was attributed to a significant reduction in membrane lipid peroxidation caused by excess $\mathrm{Mn}$ and to a significant increase in enzymatic (e.g. SOD, APX, DHAR and GR) and non-enzymatic antioxidants (e.g. ascorbate and glutathione) (Shi et al., 2005b).

The discovery that $\mathrm{Si}$ alleviated Mn phytotoxicity in turn led to the finding that this role of $\mathrm{Si}$ can also be applied to other metal ions, particularly Al (Epstein, 1999). The alleviative effect on $\mathrm{Al}$ toxicity by $\mathrm{Si}$ and its possible mechanisms have been examined most extensively. Interactions of $\mathrm{Al}$ and $\mathrm{Si}$ have been studied in at least eight plant species but contradictory findings have been reported (Hodson and Evans, 1995). Half of the eight species investigated (sorghum [Sorghum bicolor L.], barley [Hordeum vulgare L.], teosinte [Zea mays L. ssp. Mexicana], and soybean [Glycine $\max (\mathrm{L}$. Merr.]) showed significant alleviative effects of $\mathrm{Si}$ on $\mathrm{Al}$ toxicity and the others were demonstrated to exhibit little or no such effect (rice [Oryza sativa L.], wheat [Triticum aestivum L.], cotton [Gossypium hirsutum] and pea [Pisum sativum L.]). Applying $\mathrm{Si}$ has thus been suggested as an alternative approach to detoxifying $\mathrm{Al}$ toxicity in tomato (Lycopersicum esculentum L.) (Peaslee and Frink, 1969), sorghum (Sorghum bicolor L.) (Galvez et al., 1987; Galvez and Clark, 1991; Baylis et al., 1994), and barley (Hordeum vugare L.) (Hammond et al., 1995; Liang et al., 2001).

In an experiment with barley, Hammond et al. (1995) reported that $\mathrm{Si}$ exhibited significant ameliorative effects on $\mathrm{Al}$ toxicity and the amelioration was most marked where the toxic effects of $\mathrm{Al}$ were the greatest. As much as $80 \%$ amelioration of the decrease in root length was achieved using $2.8 \mathrm{mM} \mathrm{Si}$ and $50 \mu \mathrm{M} \mathrm{Al}$, and the addition of $\mathrm{Si}$ reduced $\mathrm{Al}$ uptake into the roots (Hammond et al., 1995). Baylis et al.
(1994) found that $\mathrm{Si}$ ameliorated the effects of Al toxicity in soybean, but that this was dependent on $\mathrm{pH}$. It has been established that interaction between $\mathrm{Si}$ and $\mathrm{Al}$, reducing the activity of toxic metal ions in the medium, is one possible external mechanism for the detoxification of Al toxicity by Si (Hiradate et al., 1998). Such external effects are also supported by the finding that $\mathrm{Si}$ diminished the toxicity of $\mathrm{Al}$ to soybean (Baylis et al., 1994). The precipitation of subcolloidal, inert hydroxyaluminosilicate species seems to be responsible for the diminished concentration (activity) of phytotoxic $\mathrm{Al}$ in solution. In experiments with Zea mays in which Si afforded protection against the inhibition of root elongation by $\mathrm{Al}$, Ma et al. (1997) also concluded that the formation of Al-Si complexes was responsible.

The co-deposition of $\mathrm{Si}$ with $\mathrm{Al}$ seems to occur not only in the growth media but also within plants (Birchall, 1990; Liang et al., 2001). It has been reported that added Si increased the shoot $\mathrm{Al}$ concentration, which may arise from the formation of hydroxyaluminosilicate complexes in shoots leading to enhanced Al transport from roots to shoots (Birchall, 1990). In a solution culture experiment in which a very small change in the concentration of $\mathrm{Al}$ and $\mathrm{Si}$ in solution was observed, Liang et al. (2001) believed that the co-deposition of Al and $\mathrm{Si}$ in solution was negligible because silicic acid rather than alkaline $\mathrm{Na}_{2} \mathrm{SiO}_{3}$ was used. However, co-deposition of $\mathrm{Al}$ and $\mathrm{Si}$ in the growth media using alkaline $\mathrm{Na}_{2} \mathrm{SiO}_{3}$ as $\mathrm{Si}$ source and within the plant is likely, which may be the mechanism for amelioration of $\mathrm{Al}$ toxicity by $\mathrm{Si}$ in plants grown with toxic levels of Al (Liang et al., 2001). Cocker et al. (1998a) have proposed that low-solubility aluminosilicates or hydroxyaluminosilicates (or both) are formed within the root cell wall (apoplastic) space, thereby reducing the concentration of free, toxic $\mathrm{Al}^{3+}$ ions. In experiments with teosinte, Barceló et al. (1993) found that plants exposed to toxic Al concentrations $(60 \mu \mathrm{M}$ or $120 \mu \mathrm{M})$ were less inhibited in their growth when as little as $4 \mu \mathrm{M} \mathrm{Si}$ was added to the culture solution. The mechanism for this alleviative effect was attributed mainly to the inhibitory effect of $\mathrm{Al}$ uptake by the plants. It is notable that significantly higher concentrations of malic and formic acids were observed in the plants grown in the presence of added $\mathrm{Si}$ and $\mathrm{Al}$. The same group, working with an $\mathrm{Al}$-sensitive variety of corn, Zea mays var. BR $201 \mathrm{~F}$, found that Si pretreatment was effective in counteracting the inhibition of root elongation by $\mathrm{Al}$ and diminished the absorption of $\mathrm{Al}$ by the plants (Corrales et al., 1997), suggesting a purely internal interaction between the two elements. In wheat, the mitigation of $\mathrm{Al}$ toxicity was also shown to be attributable to internal mechanisms or related to the physiological processes in plants (Cocker et al., 1998b). Silicon may have additional roles in increasing tolerance of aluminum by mediating the metabolism of phenolic compounds as it has been reported that silicon-treated maize plants release fifteen times more phenolics than untreated maize plants (Kidd et al., 2001). These flavonoid-phenolics (i.e. catechin and quercetin) have a strong Al-chelating ability and may provide metal tolerance in plants.

It is generally recognized that an external mechanism similar to Si-alleviated toxicity to $\mathrm{Al}$ applies to Si-mediated 
detoxification of $\mathrm{Cd}$ in soil/plant systems, i.e. reduction in $\mathrm{Cd}$ availability via $\mathrm{Cd}$ immobilization arising from a rise in $\mathrm{pH}$. This is true when sodium metasilicate, slag or alkaline $\mathrm{Si}$ containing materials such as biosolids are incorporated into Cd-contaminated soils as Si sources (Chen et al., 2000; Liang et al., 2005a). Chen et al. (2000) reported that furnace slag was more effective in suppressing $\mathrm{Cd}$ uptake by rice and wheat than calcium carbonate or steel sludge. They speculated that the higher $\mathrm{pH}$ and increasing available $\mathrm{Si}$ arising from the furnace slag contributed to the reduced $\mathrm{Cd}$ uptake by plants (Chen et al., 2000). The role of $\mathrm{Si}$ in minimizing uptake and root-to-shoot transport of metal ions has recently been confirmed in seedlings of rice grown with toxic $\mathrm{Cd}$ (Shi et al., 2005a) and with arsenate (Guo et al., 2005). Si also significantly reduced the transport of the apoplastic fluorescence tracer PTS (trisodium-8-hydroxy-1,3,6-pyrenesulphonate) from roots to shoots (Shi et al., 2005a), suggested that the heavy deposition of silica in the vicinity of the endodermis might offer a possible mechanism by which silicon did at least partially physically block the apoplast bypass flow across the roots, and restrained the apoplastic transport of $\mathrm{Cd}$.

In pot experiments with maize, Liang et al. (2005a) showed that Cd treatment significantly decreased shoot and root dry weights, while addition of Si significantly and greatly enhanced biomass. Silicon added at a high dosage (i.e. $400 \mathrm{mg} \mathrm{kg}^{-1} \mathrm{Si}$ ) significantly increased soil $\mathrm{pH}$ but decreased soil $\mathrm{Cd}$ availability, thereby reducing $\mathrm{Cd}$ concentrations in the shoots and roots and total $\mathrm{Cd}$ in the shoots. Moreover, more $\mathrm{Cd}$ was found to be in the form of specific adsorbed or $\mathrm{Fe}-\mathrm{Mn}$ oxides-bound fraction in the Si-amended soil. These results suggest an external interaction between $\mathrm{Si}$ and $\mathrm{Cd}$. By contrast, soil $\mathrm{pH}$ and available $\mathrm{Cd}$ were unaffected by addition of $\mathrm{Si}$ at a low dosage (i.e. $50 \mathrm{mg} \mathrm{kg}^{-1} \mathrm{Si}$ ), but shoot $\mathrm{Cd}$ concentration in the Si-amended $\mathrm{Cd}$ treatments was significantly decreased compared with the non-Si-amended $\mathrm{Cd}$ treatments, suggesting an internal mechanism for detoxification of $\mathrm{Cd}$ by $\mathrm{Si}$ occurring within plants (Liang et al., 2005a). The xylem exudates were significantly increased but the $\mathrm{Cd}$ concentration in the xylem exudates was significantly decreased in the $\mathrm{Si}$-amended $\mathrm{Cd}$ treatments compared with the non-Si-amended $\mathrm{Cd}$ treatments irrespective of the $\mathrm{Cd}$ and $\mathrm{Si}$ levels used. The results suggest that Si-enhanced $\mathrm{Cd}$ tolerance can be attributed not only to $\mathrm{Cd}$ immobilization caused by silicate-enhanced $\mathrm{pH}$ in the soils but also to $\mathrm{Si}$ mediated detoxification of $\mathrm{Cd}$ in the plants (Liang et al., 2005a). In a solution culture experiment with maize, Liang et al. found that more $\mathrm{Cd}$ was bound to the root cell walls but less to cytosols or symplast in + Si plants than in - Si plants under $\mathrm{Cd}$ stress (unpublished data), suggesting a root apoplastic role of $\mathrm{Si}$ in detoxification of excess $\mathrm{Cd}$, a mechanism similar to that responsible for the Si-mediated $\mathrm{Mn}$ tolerance in plants (Iwasaki et al., 2002a,b; Rogalla and Römheld, 2002). However, contrasting results have recently been reported by Shi et al. (2005a), who have shown that most of the total root $\mathrm{Cd}(87 \%)$ was localized in the symplasm, whereas the apoplast $\mathrm{Cd}$ accounted for only $13 \%$ of the total in both $-\mathrm{Si}$ and $+\mathrm{Si}$ treatments. Furthermore, X-ray microanalysis (EDX) showed that $\mathrm{Cd}$ was deposited mainly in the vicinity of the endodermis and epidermis, and $\mathrm{Si}$ deposition was heavier in the vicinity of the endodermis than of the epidermis (Shi et al., 2005a). The results from EDX, however, cannot explain the mechanisms underlying the Si-enhanced cadmium tolerance in rice seedlings because such low $\mathrm{Cd}$ concentrations $\left(7.85 \mu \mathrm{mol} \mathrm{Cd} \mathrm{g}{ }^{-1}\right.$ dry weight) in the roots were far below the detection limit of EDX (thousands of micrograms per gram) and could not thus have been detected by EDX (refer to Tables 1-4 and Fig. 3 of Shi et al., 2005a). We failed to detect $\mathrm{Cd}$ in maize roots containing $\mathrm{Cd}$ as high as $420 \mathrm{mg} \mathrm{Cd} \mathrm{kg}^{-1}$ using EDX (unpublished data) in a pot experiment showing Si-mediated alleviation of $\mathrm{Cd}$ toxicity in maize (Liang et al., 2005a). Evidently, further in-depth studies are needed to re-examine the micro-distribution of $\mathrm{Cd}$ in plants as influenced by $\mathrm{Si}$ using more sensitive methods such as synchrotron radiation X-ray fluorescence analysis (SRXFA). Using electron-energy-loss spectroscopy (EELS) and other techniques such as electron spectroscopic image (ESI) and EDX, Neumann and zur Nieden (2001) have reported the occurrence of co-deposition of silicon and zinc in heavy metal tolerant Cardaminopsis halleri. The formation of $\mathrm{Zn}$-silicate is part of the mechanism for tolerance to heavy metals and may be responsible for the amelioration of zinc toxicity in Cardaminopsis halleri.

Taken together, Si-mediated tolerance to metal (including $\mathrm{Al}$ and heavy metals) toxicity in plants can be summarized in Fig. 1, in which external and internal mechanisms are proposed to explain the alleviative effect of Si on metal toxicity.

\section{Mechanisms for silicon-enhanced tolerance to salinity toxicity}

Silicon has been shown to be effective in mitigating salinity in recent investigations. The mitigative effect of Si on salinity has been examined in rice (Matoh et al., 1986; Yeo et al., 1999), mesquite (Bradbury and Ahmad, 1990), wheat (Ahmad et al., 1992), barley (Liang et al., 1996, 2003, 2005c; Liang, 1998, 1999; Liang and Ding, 2002), cucumber (Zhu et al., 2004) and tomato (Al-Aghabary et al., 2004). Matoh et al. (1986) reported that shoot and root growth was severely inhibited in rice grown at $100 \mathrm{mM} \mathrm{NaCl}$ but was significantly ameliorated by addition of $\mathrm{Si}$ at $0.89 \mathrm{mM}$. Ahmad et al.

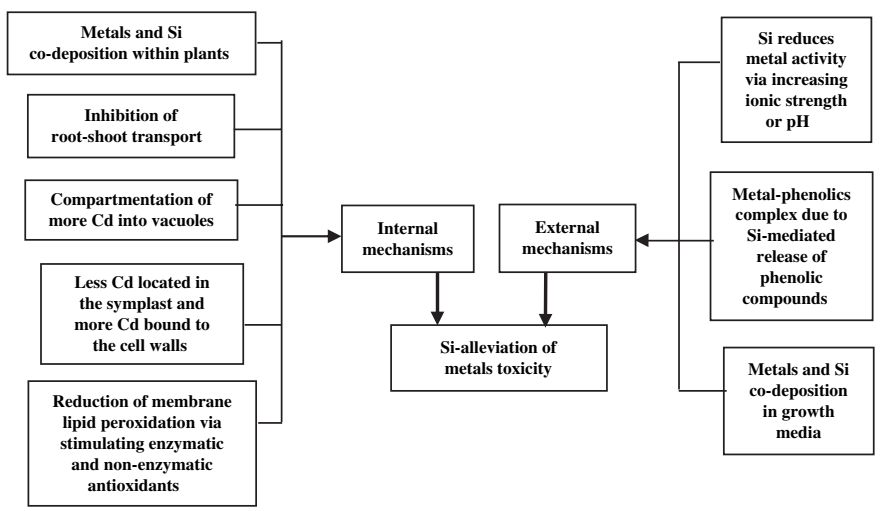

Fig. 1. Schematic hypotheses for Si-mediated tolerance to metal toxicity. 
(1992) and Bradbury and Ahmad (1990) reported that salt tolerance of wheat (Triticum aestivum) and mesquite (Prosopis juliflora) could be markedly enhanced by the addition of small amounts of soluble silicon. Liang et al. (1996) demonstrated that added silicon increased salinity tolerance of barley grown hydroponically. The Na concentration in the shoots of rice (Matoh et al., 1986; Yeo et al., 1999) and barley (Liang et al., 1996; Liang, 1999) was decreased by addition of Si. This was attributed to Si-induced reduction in transpiration rate (Matoh et al., 1986) and to the partial blockage of the transpirational bypass flow (Yeo et al., 1999). The increased uptake and transport of $\mathrm{K}^{+}$and decreased uptake and transport of $\mathrm{Na}^{+}$from roots to shoots in barley was thought to be attributable to Si-induced stimulation of the root plasma membrane $\mathrm{H}^{+}$-ATPase under salt stress (Liang et al., 1999, 2005c, 2006; Liang and Ding, 2002). Added Si decreased the permeability of the plasma membrane of leaf cells (Liang et al., 1996; Liang, 1999), and significantly improved the ultra-structure of chloroplasts which were badly damaged by the added $\mathrm{NaCl}$ with the double membranes disappearing and the grannae being disintegrated in the absence of Si (Liang, 1998). Silicon also increased leaf and root superoxide dismutase (SOD), peroxidase (POD), catalase (CAT) and glutathione reductase (GR) activities and the glutathione (GSH) concentration but suppressed the malondialdehyde (MDA) concentration in barley under salt stress and stimulated root $\mathrm{H}^{+}$-ATPase and $\mathrm{H}^{+}$PPase activity in the plasma membranes and tonoplasts and mediated membrane fluidity, suggesting that Si may affect the structure, integrity and functions of plasma membranes by influencing the stress-dependent peroxidation of membrane lipids (Liang et al., 1996, 2003, 2005c, 2006; Liang, 1999). This hypothesis (Liang, 1999; Liang et al., 2003) that Si decreased lipid peroxidation in salt-stressed plants via enhancing antioxidant enzyme activity and non-enzymatic antioxidants has recently been corroborated in experiments with cucumber (Zhu et al., 2004) and tomato (Al-Aghabary et al., 2004).

Based on the knowledge of $\mathrm{Si}$ and salinity interactions in plants, the possible mechanisms underlying Si-enhanced salinity tolerance are illustrated in Fig. 2.

\section{Perspectives}

It may be expected that the essentiality for silicon will be finally recognized in higher plants according to the newly established definition of essentiality proposed by Epstein and Bloom (2005). The most important role of this element does not lie in its general acceptance of essentiality, but rather in its most striking and unique function or role in conferring tolerance in plants to various abiotic and/or biotic stresses. Again, the most important aspect for further studies on $\mathrm{Si}$ in plant biology should be focused not only on accumulating some direct lines of evidence to demonstrate that $\mathrm{Si}$ is part of plant constituents or metabolites but also on making full use of the role of $\mathrm{Si}$ in conferring tolerance in plants against abiotic stresses, and thus its role in environmental remediation. The former is vital to understanding the roles of $\mathrm{Si}$ in plant biology, while the latter is highly conducive to developing

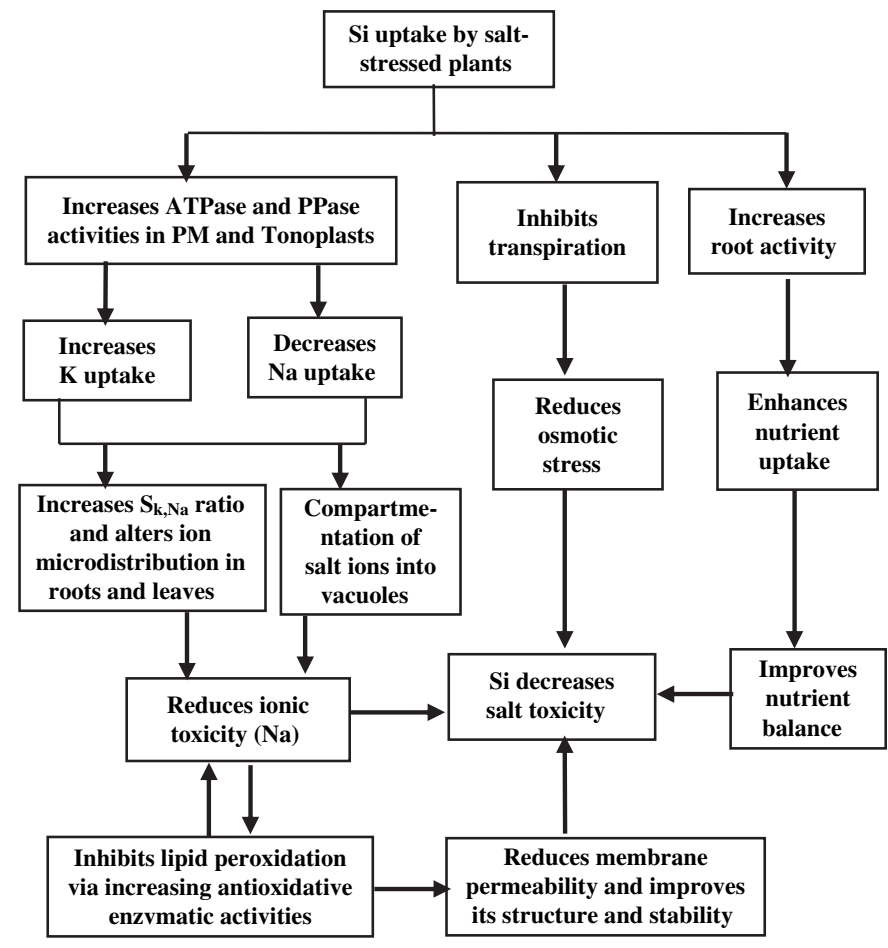

Fig. 2. Possible mechanisms for Si-mediated tolerance to salinity toxicity.

high yields and quality, and cost-effective and environmentally benign agriculture. The last but not the least will be the mechanism for Si uptake and xylem loading in higher plants, which is also the basis for better insight into the role Si plays in plant physiology (stress physiology in particular) and biochemistry. More recently, rapid progress has been made in cloning and characterization of the gene encoding Si-transporter in rice, a typical Si-accumulating plant (Ma et al., 2002, 2006; Tamai and Ma, 2003; Ma, 2004). However, no in-depth investigations have been performed on characterizing Si uptake and transport in root systems of Si-accumulating plants other than cucumber, in which Si uptake and transport has recently been reported to be an active process (Liang et al., 2005b).

Based on current knowledge, it can be concluded that $\mathrm{Si}$ is not inert, but acts as a physical or mechanical barrier in plants. It is not only deposited in the cell walls, but is also actively involved in the metabolic and/or physiological activities, especially in plants subject to multiple stresses.

\section{Acknowledgments}

This research was supported by grants from National Natural Science Foundation of China (Nos. 39470424, 39770441, 39970430, 30170536, 30471030), the Ministry of Science and Technology (2004BA520A13-6), the Natural Science Foundation of Beijing (6052023) and the International Foundation For Science (Nos. C/2528-1 and C/2528-2). It was also supported by a grant from the Distinguished Talent Program of the Chinese Academy of Agricultural Sciences granted to Y.L. 


\section{References}

Al-Aghabary, K., Zhu, Z., Shi, Q.H., 2004. Influence of silicon supply on chlorophyll content, chlorophyll fluorescence, and antioxidative enzyme activities in tomato plants under salt stress. J. Plant Nutr. 27, 2101-2115.

Ahmad, R., Zaheer, S.H., Ismail, S., 1992. Role of silicon in salt tolerance of wheat (Tritium aestivum L.). Plant Sci. 85, 43-50.

Arnon, D.I., Stout, P.R., 1939. The essentiality of certain elements in minute quantity for plants with special reference to copper. Plant Physiol 14, 371-375.

Barber, D.A., Shone, M.G.T., 1966. The absorption of silica from aqueous solutions by plants. J. Exp. Bot 17, 569-578.

Barceló, J., Guevara, P., Poschenrieder, C., 1993. Silicon amelioration of aluminum toxicity in teosinte, Zea mays L. ssp. mexicana. Plant Soil 154 249-255.

Baylis, A.D., Gragopoulou, C., Davidson, K.J., Birchall, J.D., 1994. Effects of silicon on the toxicity of aluminum to soybean. Commun. Soil Sci Plant Anal 25, 537-546.

Birchall, J.D., 1990. The role of silicon in biology. Chem. Britain 26, 141144.

Bradbury, M., Ahmad, R., 1990. The effect of silicon on the growth of Prosopis juliflora growing in saline soil. Plant Soil 125, 71-74.

Casey, W.H., Kinrade, S.D., Knight, C.T.G., Rains, D.W., Epstein, E., 2003. Aqueous silicate complexes in wheat, Triticum aestivum L. Plant Cell Environ. 27, 51-54.

Chen, H.M., Zheng, C.R., Tu, C., Shen, Z.G., 2000. Chemical methods and phytoremediation of soil contaminated with heavy metals. Chemosphere 41, 229-234.

Cocker, K.M., Evans, D.E., Hodson, M.J., 1998a. The amelioration of aluminium toxicity by silicon in higher plants: solution chemistry or an in plants mechanism? Physiol. Plant. 104, 608-614.

Cocker, K.M., Evans, D.E., Hodson, M.J., 1998b. The amelioration of aluminium toxicity by silicon in wheat (Triticum aestivum L.): malate exudation as evidence for an in planta mechanism. Planta 204, 318-323.

Corrales, I., Poschenrieder, C., Barceló, J., 1997. Influence of silicon pretreatment on aluminium toxicity in maize roots. Plant Soil 190, 203-209.

Epstein, E., 1994. The anomaly of silicon in plant biology. Proc. Natl. Acad. Sci. USA 91, 11-17.

Epstein, E., 1999. Silicon. Annu. Rev. Plant Physiol. Plant Mol. Biol. 50, 641664.

Epstein, E., Bloom, A.J., 2005. Mineral Nutrition of Plants: Principles and Perspectives, second ed. Sinauer, Sunderland, MA.

Galvez, L., Clark, R.B., 1991. Effects of silicon on growth and mineral composition of sorghum (Sorghum bicolor) grown with toxic levels of aluminium. In: Wright, R.J., et al. (Eds.), Plant-Soil Interactions at Low pH. Kluwer Academic Publishers, Dordrecht, The Netherlands, pp. 815-823.

Galvez, L., Clark, R.B., Gourley, L.M., Maranville, J.W., 1987. Silicon interactions with manganese and aluminum toxicity in sorghum. J. Plant Nutr $10,1139-1147$.

Gong, H.J., Zhu, X.Y., Chen, K.M., Wang, S.M., Zhang, C.L., 2005. Silicon alleviates oxidative damage of wheat plants in pots under drought. Plant Sci. 169, 313-321.

Guo, W., Hou, Y.L., Wang, S.G., Zhu, Y.G., 2005. Effect of silicate on the growth and arsenate uptake by rice (Oryza sativa $\mathrm{L}$.) seedlings in solution culture. Plant Soil 272, 173-181.

Hammond, K.E., Evans, D.E., Hodson, M.J., 1995. Aluminium/silicon interactions in barley (Hordeum vulgare L.) seedlings. Plant Soil 173, 89-95.

Hiradate, S., Taniguchi, S., Sakurai, K., 1998. Aluminum speciation in aluminum-silica solutions and potassium chloride extracts of acidic soils. Soil Sci. Soc. Am. J 62, 630-636.

Hodson, M.J., Evans, D.E., 1995. Aluminium/ silicon interactions in higher plants. J. Exp. Bot 46, 161-171.

Horiguchi, T., Morita, S., 1987. Mechanism of manganese toxicity and tolerance of plants. VI. Effect of silicon on alleviation of manganese toxicity of barley. J. Plant Nutr 10, 2299-2310.

Horst, W.J., Marschner, H., 1978. Effect of silicon on manganese tolerance of bean plants (Phaseolus vulgaris L.). Plant Soil 50, 287-303.
Horst, W.J., Fecht, M., Naumann, A., Wissemeier, A.H., Maier, P., 1999. Physiology of manganese toxicity and tolerance in Vigna unguiculata (L.) Walp. J. Plant Nutr Soil Sci. 162, 263-274.

Iwasaki, K., Matsumura, A., 1999. Effect of silicon on alleviation of manganese toxicity in pumpkin (Cucurbita moschata Duch cv. Shintosa). Soil Sci. Plant Nutr 45, 909-920.

Iwasaki, K., Maier, P., Fecht, M., Horst, W.J., 2002a. Effects of silicon supply on apoplastic manganese concentrations in leaves and their relation to manganese tolerance in cowpea (Vigna unguiculata (L.) Walp.). Plant Soil 238, 281-288.

Iwasaki, K., Maier, P., Fecht, M., Horst, W.J., 2002b. Leaf apoplastic silicon enhances manganese tolerance of cowpea (Vigna unguiculata). J. Plant Physiol 159, 167-173.

Jarvis, S.C., 1987. The uptake and transport of silicon by perennial ryegrass and wheat. Plant Soil 97, 429-437.

Jones, L.H.P., Handreck, K.A., 1965. Studies of silica in the oat plant. III. Uptake of silica from soils by the plant. Plant Soil 23, 79-99.

Jones, L.H.P., Handreck, K.A., 1967. Silica in soils, plants and animals. Adv. Agron 19, 107-149.

Kidd, P.S., Llugany, M., Poschenrieder, C., Gunse, B., Barcelo, J., 2001. The role of root exudates in aluminium resistance and silicon-induced amelioration of aluminium toxicity in three varieties of maize (Zea mays L.). J. Exp. Bot 52, 1339-1352.

Lewin, J., Reimann, B.E.F., 1969. Silicon and plant growth. Annu. Rev. Plant Physiol 20, 289-304.

Liang, Y.C., 1998. Effects of Si on leaf ultrastructure, chlorophyll content and photosynthetic activity in barley under salt stress. Pedosphere 8, 289-296.

Liang, Y.C., 1999. Effects of silicon on enzyme activity, and sodium, potassium and calcium concentration in barley under salt stress. Plant Soil 209, 217-224.

Liang, Y.C., Ding, R.X., 2002. Influence of silicon on microdistribution of mineral ions in roots of salt-stressed barley as associated with salt tolerance in plants. Sci. China (Series C) 45, 298-308.

Liang, Y.C., Shen, Q.R., Shen, Z.G., Ma, T.S., 1996. Effects of silicon on salinity tolerance of two barley cultivars. J. Plant Nutr 19, 173-183.

Liang, Y.C., Yang, C.G., Shi, H.H., 2001. Effects of silicon on growth and mineral composition of barley grown under toxic levels of aluminum. J. Plant Nutr 24, 229-243.

Liang, Y.C., Chen, Q., Liu, Q., Zhang, W.H., Ding, R.X., 2003. Exogenous silicon $(\mathrm{Si})$ increases antioxidant enzyme activity and reduces lipid peroxidation in roots of salt-stressed barley (Hordeum vulgare L.). J. Plant Physiol $160,1157-1164$

Liang, Y.C., Wong, J.W.C., Wei, L., 2005a. Silicon-mediated enhancement of cadmium tolerance in maize (Zea mays L.) grown in cadmium contaminated soil. Chemosphere 58, 475-483.

Liang, Y.C., Si, J., Römheld, V., 2005b. Silicon uptake and transport is an active process in Cucumis sativus L. New Phytol 167, 797-804.

Liang, Y.C., Zhang, W.H., Chen, Q., Ding, R.X., 2005c. Effects of silicon on tonoplast $\mathrm{H}^{+}$-ATPase and $\mathrm{H}^{+}$-PPase activity, fatty acid composition and fluidity in roots of salt-stressed barley (Hordeum vulgare L.). Environ. Exp. Bot 53, 29-37.

Liang, Y.C., Zhang, W.H., Chen, Q., Liu, Y.L., Ding, R.X., 2006. Effect of exogenous silicon $(\mathrm{Si})$ on $\mathrm{H}^{+}$-ATPase activity, phospholipids and fluidity of plasma membrane in leaves of salt-stressed barley (Hordeum vulgare L.). Environ. Exp. Bot 57, 212-219.

Liang, Y.C., Hua, H.X., Zhu, Y.G., Zhang, J., Cheng, C.M., Römheld, V. Importance of plant species and external silicon concentration to active silicon uptake and transport. New Phytol, in press. doi:10.1111/j. 1469-8137.2006.01797.x.

Ma, J.F., 2004. Role of silicon in enhancing the resistance of plants to biotic and abiotic stresses. Soil Sci. Plant Nutr 50, 11-18.

Ma, J.F., Sasaki, M., Matsumoto, H., 1997. Al-induced inhibition of root elongation in corn, Zea mays L. is overcome by Si addition. Plant Soil 188, 171-176.

Ma, J.F., Miyake, Y., Takahashi, E., 2001a. Silicon as a beneficial element for crop plants. In: Datnoff, L., Snyder, G., Korndorfer, G. (Eds.), Silicon in Agriculture. Elsevier Science, New York, pp. 17-39. 
Ma, J.F., Goto, S., Tamai, K., Ichii, M., 2001b. Role of root hairs and lateral roots in silicon uptake by rice. Plant Physiol 127, 1773-1780.

Ma, J.F., Tamai, K., Ichii, M., Wu, G.F., 2002. A rice mutant defective in Si uptake. Plant Physiol 130, 2111-2117.

Ma, J.F., Tamai, K., Yamaji, N., Mitani, N., Konishi, S., Katsuhara, M., Ishiguro, M., Murata, Y., Yano, M., 2006. A Si transporter in rice. Nature 440, 688-691.

Matoh, T., Kairusmee, P., Takahashi, E., 1986. Salt-induced damage to rice plants and alleviation effect of silicate. Soil Sci. Plant Nutr 32, 295-304.

Mitani, N., Ma, J.F., 2005. Uptake system of silicon in different plant species. J. Exp. Bot 56, 1255-1261.

Neumann, D., zur Nieden, U., 2001. Silicon and heavy metal tolerance of higher plants. Phytochemistry 56, 685-692.

Okuda, A., Takahashi, E., 1962. Effect of silicon supply on the injuries due to excessive amounts of $\mathrm{Fe}, \mathrm{Mn}, \mathrm{Cu}, \mathrm{As}, \mathrm{Al}, \mathrm{Co}$ of barley and rice plant. Jpn. J. Soil Sci. Plant Nutr 33, 1-8 (in Japanese).

Peaslee, D.E., Frink, C.R., 1969. Influence of silicic acid on uptake of Mn, Al, $\mathrm{Zn}$, and $\mathrm{Cu}$ by tomatoes (Lycopersicum esculentum) grown on an acid soil. Soil Sci. Soc. Am. Proc. 33, 569-571.

Rogalla, H., Römheld, V., 2002. Role of leaf apoplast in silicon-mediated manganese tolerance of Cucumis sativus L. Plant Cell Environ 25, 549-555.

Shi, X.H., Zhang, C.C., Wang, H., Zhang, F.S., 2005a. Effect of Si on the distribution of $\mathrm{Cd}$ in rice seedlings. Plant Soil 272, 53-60.
Shi, Q.H., Bao, Z.Y., Zhu, Z.J., He, Y., Qian, Q.Q., Yu, J.Q., 2005b. Siliconmediated alleviation of Mn toxicity in Cucumis sativus in relation to activities of superoxide dismutase and ascorbate peroxidase. Phytochemistry $66,1551-1559$.

Takahashi, E., Ma, J.F., Miyake, Y., 1990. The possibility of silicon as an essential element for higher plants. Comments Agric Food Chem. 2, 357-360.

Tamai, K., Ma, J.F., 2003. Characterization of silicon uptake by rice roots New Phytol. 158, 431-436.

Van der Vorm, P.D.J., 1980. Uptake of Si by five plant species, as influenced by variation in Si-supply. Plant Soil 56, 153-156.

Williams, D.E., Vlamis, J., 1957a. Manganese toxicity in standard culture solutions. Plant Soil 8, 183-193.

Williams, D.E., Vlamis, J., 1957b. The effect of silicon on yield and manganese-54 uptake and distribution in the leaves of barley plants grown in culture solutions. Plant Physiol 32, 404-409.

Yeo, A.R., Flowers, S.A., Rao, G., Welfare, K., Senanayake, N., Flowers, T.J., 1999. Silicon reduces sodium uptake in rice (Oryza sativa L.) in saline conditions and this is accounted for by a reduction in the transpirational bypass flow. Plant Cell Environ. 22, 559-565.

Zhu, Z.J., Wei, G.Q., Li, J., Qian, Q.Q., Yu, J.Q., 2004. Silicon alleviates salt stress and increases antioxidant enzymes activity in leaves of salt-stressed cucumber (Cucumis sativus L.). Plant Sci. 167, 527-533. 